\title{
RELATIONS OF THE COMPRESSIVE PROPERTIES OF HUMAN CORTICAL BONE TO HISTOLOGICAL STRUCTURE AND CALCIFICATION*†
}

\author{
F. GAYNOR EVANS \\ Department of Anatomy, University of Michigan. Ann Arbor, Michigan 48104. U.S.A.
}

and

R. VINCLNTELLI

Catedra de Histologia y Embriologia. Facultad de Odontologia, Lniversidad Central de Venezuela. Caracas. Venezuela

\begin{abstract}
Compressive properties were determined for 65 standardized specimens of wet, unembalmed cortical bone from tibias of six men. Osteons were classified as dark. light or intermediate from their appearance in polarized light and as slightly, intermediately or markedly radiolucent from their appearance in microradiographs. Compressive strength had significant pusitive cortelations with the percent of intermediate osteons or slightly radiolucent osteons in the cross section. Significant negative correlations occurred between compressive strength and percent of spaces. Compressive strain had a significant positive correlation with the percent of light osteons. Multiple correlation coefficients between compressive strength or strain and the various histologic and microradiographic variables were higher and more significant than that found with elastic modulus as the dependent variable. The significant positive correlation between compressive strength and the percent of osteons, regardless of their collagen fiber orientation in the cross-section, suggests that osteons tend to increase the compressive strength of bone.
\end{abstract}

\section{INTRODLICTION}

Considerable data are available in the literature on the relations of some of the mechanical properties of human cortical bone to its microscopic structure. Dempster and Coleman (1961) reported that the tensile and bending strength of specimens from adult human tibias and mandibles were greater along than across the grain of the bone. Bone grain, indicating the orientation of the osteons, was determined by the carbon infiltration method of Avery et al. (1959).

Evans and Bang $(1966,1967)$, working with cortical hone specimens from embalmed adult human femurs. tibias and fibulas, found significant positive correlations between tensile strength and the percentage of interstitial lamellae in the break ared. Similar correlations were found between Rockwell superficial hardness and the percentage of osteons in the break area as well as the number of osteons $/ \mathrm{mm}^{2}$. Significant negative correlations occurred between tensile strength and the percentage of osteons in the break area and between

* Received $25 \mathrm{Jt} / \mathrm{l} 1973$.

† This research was supported (in part) by Research Grant AM-0.3865 from the National Institutes of Health and by Research Grant 353 from Consejo de Desarrollo Cientifico $y$ Humanistico, Central University of Vene/ucla.

B.M. Vol. 7. Vo. I A single shearing strength and the a verage size of the osteon remnants (i.e. the cross-sectional area of the remnant). Modulus of elasticity and Rockwell superficial hardness had significant negative correlations with the percentage of spaces in the break area. These results suggest that osteons tend to reduce tensile strength and elastic modulus of bone while interstitial lamellae tend to increase them. Osteons tend to increase the hardness of bone, also, while spaces reduce it.

According to Evans and Riolo (1970) the fatigue life number of cycles to failure at a constant stresst of unembalmed bone from adult human tibias hats at significant positive correlation with the percentage of ostcons and of osteons plus remnants in the break area. Fqually significant negative correlations were found between fatigue life and the percentage of the break area formed by interstitial lamellae. These data imply that osteons and their remnants increase fatigue life of bone while interstitial lamellae decrease it.

The relations of collagen fiber orientation and of calcification to the tensile, compressive and shearing properties of bone were studied by Ascenzi and Bonucei $(1967,1968,1972)$ in individual human and bovine osteons. Tensile strength and modulus of elasticity appeared to be higher in osteons whose collagen fibers had a markedly longitudinal arrangement than in those 
whose fiber bundles in successive lamellae changed through a $90^{\circ}$ angle. Tensile strain showed the opposite relations to collagen fiber orientation. Ultimate compressive strength and modulus of elasticity were greatest in osteons with predominantly circularly or transversely oriented collagen fibers and lowest in those whose collagen fibers were primarily longitudinal in orientation. Osteons with predominantly circular fibers had a higher shearing strength than those with longitudinally oriented fibers. In osteons of the same type, shearing strength was much lower than tensile or compressive strength. The modulus of elasticity in wettested osteons increased with greater degrees of calcification.

The relations of the tensile properties of standardized specimens of cortical bone from unembalmed adult human tibias to their collagen fiber orientation and degree of calcification were investigated by Vincentelli and Evans (1971). Their results agree with those of Ascenzi and Bonucci for single osteons in that a fairly high negative correlation was found between ultimate tensile strength and strain and the percentage of the break area formed by osteons with more circularly (transversely) oriented collagen fibers. The same mechanical properties had positive correlations with the percentage of the break area formed by osteons with more longitudinally oriented collagen fibers. No significant correlations were found between modulus of elasticity and any of the osteon types. An analysis of variance in the degree of calcification revealed no highly significant correlations of this variable with any of the mechanical properties.

The investigations briefly reviewed above show that significant correlations exist between the tensile, shearing and fatigue properties of human cortical bone and its microscopic structure. The present study was undertaken to determine if compressive properties of adult human cortical bone also have significant correlations with its microscopic structure.

\section{MATERIALS AND METHODS}

The ultimate compressive stress, strain and modulus of elasticity were determined for 65 specimens of cortical bone machined to a standardized size and shape ( 76.2 long, 6.3 wide and $2.3 \mathrm{~mm}$ thick) from the various thirds and quadrants of unembalmed tibias from above-knee amputations of six Caucasian men. A jig (Fig. 1), specially designed to prevent buckling, held the specimens while they were loaded to failure at a constant speed of $0.045 \mathrm{in} / \mathrm{min}$ in a $5,000 \mathrm{lb}$ capacity Riehle materials testing machine calibrated to an accuracy of \pm 0.5 per cent. During a test, the low range scale of the testing machine $(0-250 \mathrm{lb})$ was used so that the load was recorded on the dial of the machine in units of $0.5 \mathrm{lb}$. The load was applied to the end of the specimen protruding above the jig and failure was indicated by a dropping off of load recorded on the testing machine.

Compressive strain occurring in a specimen during a test was measured over a gauge length of $1 \mathrm{in}$. with two Porter-Lipp extensometers, calibrated in units of 0.0001 in., attached to opposite edges of the specimen through slits in the jig. From the stress-strain data obtained in a test, a stress-strain diagram was plotted from which the tangent modulus of elasticity was calculated.

Elongated test specimens, with a rectangular crosssection, were used in preference to cubic ones because with cubic specimens there is a tendency for the upper half to become impacted into the lower half. If this occurs, abnormally high values for compressive stress and strain may result. All spccimens were wet when tested.

Cross-sections of the specimens, taken as close as possible to the fracture site, were studied by means of microradiography and the polarizing light microscope. Histological analysis of the sections were made with the same methods employed by Evans and Bang (1966, 1967) and by Vincentelli and Evans (1971).

Ostcons and their fragments were classified as being slightly, intermediately or markedly radiolucent on the basis of their appearance in the microradiographs. The percentage of the cross-sectional area of the specimen formed by these three types of osteons and fragments was then calculated from enlarged prints of the microradiographs.

From the appearance of their lamellae in polarized light, osteons and their fragments were categorized as light, intermediate or dark. Light osteons have a regular alternation of light and dark lamellae while in dark osteons almost all lamellae appear dark. In intermediate osteons, areas with the lamellar arrangement of light osteons alternate with areas where only dark lamellae are encountered. In order for collagen fibers to appear light they must be fairly parallel to the plane of the cross-section bcing studied. Thus, in light lamellae the collagen fibers are more or less circularly oriented with a low angle of spiral around the long axis of the osteon. In dark lamellae the collagen fibers have a high angle of spiral around the long axis of the osteon with which they are almost parallel, and are approximately perpendicular to the plane of the crosssection. Enlarged prints of the photomicrographs taken under polarized light were analyzed with respect to the percentage of the cross-sectional area formed by major spaces (Haversian canals, Volkmann's canals, resorption lacunae) and by light, intermediate and dark 


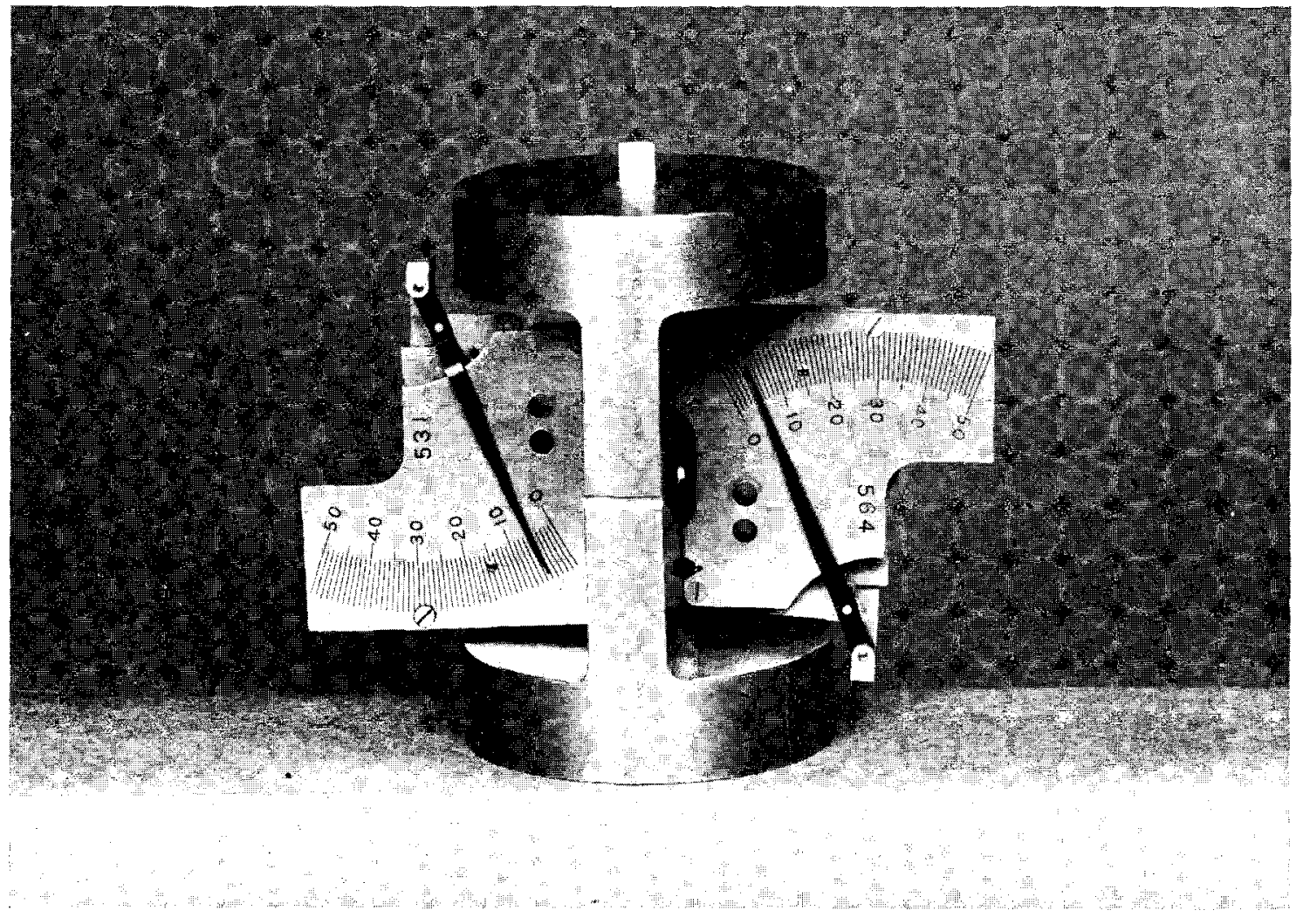

FIG. 1.

(Facing p. 2) 


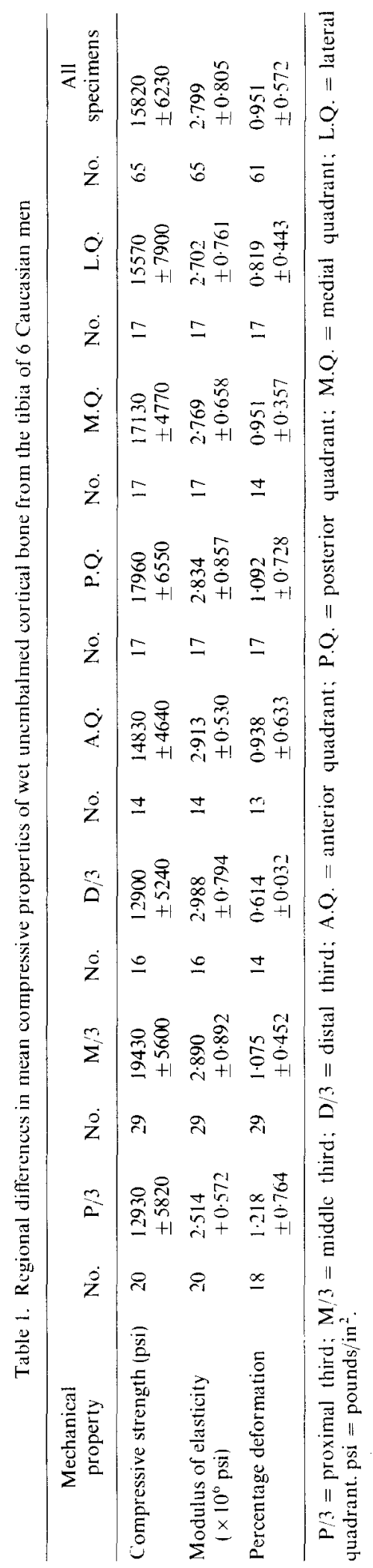


Table 2. Age differences in mean compressive properties of wet unembalmed cortical bone from the tibias of 6 Caucasian men

\begin{tabular}{|c|c|c|c|c|c|c|}
\hline $\begin{array}{l}\text { Age } \\
\text { (yr) }\end{array}$ & No. & $\begin{array}{l}\text { Compressive } \\
\text { strength } \\
\text { (psi) }\end{array}$ & No. & $\begin{array}{l}\text { Modulus of } \\
\text { elasticity } \\
\left(\times 10^{6} \text { psi }\right)\end{array}$ & No. & $\begin{array}{l}\text { Percentage } \\
\text { deformation }\end{array}$ \\
\hline 26 & 12 & $10460 \pm 5400$ & 12 & $3.386 \pm 1.061$ & 9 & $0.69 \pm 0.475$ \\
\hline 31 & 7 & $22970 \pm 5370$ & 7 & $2.899 \pm 0.872$ & 7 & $0.926 \pm 0.237$ \\
\hline 54 & 7 & $22320 \pm 4230$ & 7 & $2.529 \pm 0.312$ & 8 & $1.25 \pm 0.597$ \\
\hline 61 & 9 & $17450 \pm 4100$ & 9 & $2.759 \pm 1.298$ & 9 & $0.656 \pm 0.225$ \\
\hline 75 & 20 & $15230 \pm 3550$ & 20 & $2.675 \pm 0.806$ & 19 & $1.294 \pm 0.666$ \\
\hline$?$ & 10 & $12420 \pm 6010$ & 10 & $2.500 \pm 0.534$ & 10 & $0.604 \pm 0.265$ \\
\hline
\end{tabular}

psi $=$ pounds $/ \mathrm{in}^{2}$.

osteons and their fragments. Continuous reference was made to the original section during this analysis.

Correlation coefficients between the mechanical properties of the specimens and their various histological components were calculated for both the original and the corrected cross-sectional area of the specimens. The original cross-sectional area was the total area including all the spaces while the corrected crosssectional area was the area after the major spaces were excluded. Comparison of the correlation coefficients based on the two kinds of cross-sectional areas showed no significant differences. Consequently, only the coefficients based on the original cross-sectional area were used. In order to be considered significant, correlations had to be at the 0.01 or better significance level.

\section{RESULTS}

Mechanical property data obtained in the tests showed that specimens from the middle third and the posterior quadrant of the shaft had the highest mean compressive strength while the lowest mean strength was found in specimens from the distal third and anterior quadrant of the bone (Table 1). However, the difference between the mean strength of the proximal and distal third specimens was slight. Mean modulus of elasticity was greatest in distal third and anterior

Table 3. Histologic variables of 65 specimens of cortical bone from the tibia of 6 Caucasian men, expressed in percentages of cross-sectional area

\begin{tabular}{lrr}
\hline & Mean & \multicolumn{1}{c}{ S.D. } \\
\hline Light osteons & 8.475 & 6.941 \\
Intermediate osteons & 17.991 & $9 \cdot 351$ \\
Dark osteons & 23.498 & 13.555 \\
Light fragments & 4.560 & $5 \cdot 040$ \\
Intermediate fragments & 10.755 & 7.378 \\
Dark fragments & 14.886 & $8 \cdot 076$ \\
Interstitial lamellae & $12 \cdot 265$ & 15.473 \\
Spaces & 7.529 & 4.397 \\
\hline
\end{tabular}

Table 4. Areas of bone tissue with increased radiolucency in microradiographs of cross sections of 65 specimens of cortical hone from the tibia of 6 Caucasian men. expressed in percentages of cross-sectional area

\begin{tabular}{lcc}
\hline Radiolucency & Mean & S.D. \\
\hline Slight & 30.229 & 11.434 \\
Intermediate & 21.600 & $10 \cdot 945$ \\
Marked* & 2.528 & $2 \cdot 853$
\end{tabular}

* Spaces not included.

quadrant specimens and least in those from the proximal third and lateral quadrant. Proximal third and posterior quadrant specimens had the highest and middle third and lateral quadrant specimens the lowest percentage deformation.

Among the five men of known age, mean compressive strength was least in the 26-yr-old subject. then increased to a maximum in the 31 -yr-old man after which it steadily declined with advancing age (Table 2). Mean modulus of elasticity was greatest in the 26-yr-old man but after that steadily declined with age except for the 54-yr-old man who had the lowest mean modulus of all. Mean percentage deformation increased from 26 to $54 \mathrm{yr}$ of age, declined to a minimum in the $61-\mathrm{yr}$-old man, then increased to a maximum in the 75-yr-old subject.

Data obtained in the polarized light studies revealed that the dark osteons and their fragments formed the largest while the light osteons and their fragments formed the smallest mean percentage of the crosssectional area of the specimens (Table 3). A similar analysis of the microradiographs revealed that the largest and the smallest mean percentage of the crosssectional area were formed by the slightly and the markedly radiolucent areas, respectively (Table 4).

Linear correlation coefficients between each of the mechanical properties and the percentages of the crosssectional area formed by spaces and by histological components with different collagen fiber orientations 
Table 5. Linear correlation coeflicients between compressive properties of cortical bone from the libias of 6 (aucasian men and cross-sectional aleal percen lages formed by different histologic variables

\begin{tabular}{lccc}
\hline \multicolumn{1}{c}{$\begin{array}{c}\text { Ultimate } \\
\text { Compressive } \\
\text { stress } \\
(N=65)\end{array}$} & $\begin{array}{c}\text { Modulus } \\
\text { of } \\
\text { variable }\end{array}$ & $(N=65$ & $\begin{array}{c}\text { Compressive } \\
\text { strain } \\
(N=61)\end{array}$ \\
\hline Light osteons & -0.146 & -0.110 & $0.483+$ \\
Intermediate osteons & $0.333^{*}$ & -0.113 & 0.131 \\
Dark osteons & 0.261 & -0.019 & -0.114 \\
Light fragments & -0.312 & -0.016 & 0.160 \\
Intermediate fragments & 0.042 & -0.009 & 0.145 \\
Dark fragments & -0.238 & 0.137 & -0.135 \\
Interstitial lamellae & 0.028 & 0.099 & 0.195 \\
Spaces & $-0.655+$ & -0.098 & -0.256 \\
\hline
\end{tabular}

$*=p<0.01 ; \dagger=p<0.001$.

revealed several significant relations (Table 5). The most significant correlations $(p<0.001)$ were found between ultimate compressive strength and spaces $(r=-0.655)$ and between compressive strain and light osteons $(r=0.483)$. Another significant correlation $(p<0.01)$ was between ultimate compressive strength and intermediate osteons $(r=0.333)$. The correlation between the compressive strength and spaces was negative but the other correlations were positive.

When the area percentages formed by osteons and by osteon fragments of the same type were added and correlation coefficients with the mechanical properties determined, the results varied somewhat from those for osteons alone and were generally lower (Table 6). The only significant correlation $(p<0.01)$ was a positive one between light osteons plus fragments and compressive strain $(r=0.388)$.

Linear correlation coefficients computed between the percentage of the break area formed by areas with different degrees of calcification (as judged from their microradiographs) and mechanical properties were found to be significant $(p<0.01)$ only in two instances: i.e. between slightly radiolucent areas and ultimate compressive strength $(r=0.341)$ and between markedly radiolucent areas the modulus of elasticity $(r=0.323)$ (Table 7). Both correlations were positive.
In contrast to the majority of our specimens, which consisted predominantly of haversian bone, some of them were formed mainly by circumferential lamellae with just a few osteons interspersed among them. In order to have a sample consisting predominantly of haversian bone, 14 specimens in which interstitial lamellae constituted more than 25 per cent of the crosssectional area were excluded. Linear correlation coefficients between the mechanical properties and the percentage of the cross-sectional area formed by different osteon types were then calculated for the remaining 51 specimens. It was found that the correlation between ultimate compressive strength and in termediate osteons was substantially higher $(r=0 \cdot 504)$ while that between compressive strain and light osteons was slightly lower $(r=0.465)$, although still significant $(p<0.001)$. No other significant correlations were found (Table 8). Both correlations were positive. The correlation coefficient between ultimate compressive strength and the percentage of spaces in the cross-sectional area was significant $(p<0.001)$, its actual value being $r=-0.727$.

As our specimens were taken from 6 bones only. the possibility that individual variations between these bones that were not accounted for might be affecting our calculations was considered. Therefore, correlation coefficients were computed between the compressive

Table 6. Linear correlation coefficients between compressive properties of cortical bone from the tibias of 6 Caucasian men and cross-sectional area percentages formed by different types of osteons and fragments

\begin{tabular}{lccc}
\hline & $\begin{array}{c}\text { Ultimate } \\
\text { compressive } \\
\text { strength }\end{array}$ & $\begin{array}{c}\text { Modulus of } \\
\text { elasticity }\end{array}$ & $\begin{array}{c}\text { Compressive } \\
\text { strain }\end{array}$ \\
\hline $\begin{array}{l}\text { Light osteons and fragments } \\
\text { Intermediate osteons and } \\
\text { fragments }\end{array}$ & -0.238 & -0.078 & $0.388^{*}$ \\
Dark osteons and fragments & 0.232 & -0.075 & 0.153 \\
\end{tabular}

$*=p<0.01$. 
Table 7. Linear correlation coefficients between compressive properties of cortical bone from the tibias of 6 Caucasian men and cross-sectional area percentages formed by osteons and fragments with different degrees of calcification (see discussion for explanation)

\begin{tabular}{lccc}
\hline & $\begin{array}{c}\text { Ultimate } \\
\text { compressive } \\
\text { strength } \\
(N=65)\end{array}$ & $\begin{array}{c}\text { Modulus } \\
\text { of } \\
\text { elasticity } \\
(N=65)\end{array}$ & $\begin{array}{c}\text { Compressive } \\
\text { strain } \\
(N=61)\end{array}$ \\
\hline $\begin{array}{l}\text { Osteons and fragments with: } \\
\begin{array}{c}\text { Slight radiolucency } \\
\text { (almost fully calcified) }\end{array}\end{array}$ & $0.341^{*}$ & -0.127 & 0.014 \\
$\begin{array}{l}\text { Intermediate radiolucency } \\
\text { (less calcified) }\end{array}$ & -0.065 & -0.081 & -0.030 \\
$\begin{array}{c}\text { Marked radiolucency } \\
\text { (least calcified) }\end{array}$ & -0.206 & $0.373 \dagger$ & -0.096 \\
\hline
\end{tabular}

$*=p<0.01 ; N=$ No. of specimens.

properties and the different osteon types for each individual bone. Because correlation coefficients cannot be average directly they were converted into Fischer's $z$ functions and correlation coefficients for the entire 65 specimens derived from the weighted means (Table 9). Significant positive correlations were found between ultimate compressive strength and intermediate osteons $(p<0.001)$ and between compressive strain and light osteons $(p<0 \cdot 01)$.

A similar analysis of the specimens in which interstitial lamellae constituted less than 25 per cent of the cross-sectional area showed a high significant correla- tion between ultimate compressive strength and intermediate osteons $(p<0.01)$ and between compressive strain and light osteons $(p<0 \cdot 02)$. Both correlations were positive (Table 10).

Multiple correlations were finally calculated using the different mechanical properties as dependent variables and as many histological components of the specimens as would make a significant difference as the independent variables. The adjusted multiple correlation coefficients revealed significant correlations between each of the three mechanical properties (ultimate compressive strength, modulus of elasticity,

Table 8. Linear correlation coefficients between compressive properties of cortical bone specimens containing over 75 per cent haversian bone, obtained from tibias of 6 Caucasian men, and cross-sectional area percentages formed by different types of osteons

\begin{tabular}{lccc}
\hline & $\begin{array}{c}\text { Ultimate } \\
\text { compressive } \\
\text { strength } \\
(N=51)\end{array}$ & $\begin{array}{c}\text { Modulus of } \\
\text { elasticity } \\
(N=51)\end{array}$ & $\begin{array}{c}\text { Compressive } \\
\text { strain } \\
(N=48)\end{array}$ \\
\hline Light osteons & $-0 \cdot 177$ & $-0 \cdot 113$ & $0 \cdot 465^{*}$ \\
Intermediate osteons & $0 \cdot 504 \dagger$ & $-0 \cdot 064$ & $0 \cdot 084$ \\
Dark osteons & 0.095 & $0 \cdot 050$ & $-0 \cdot 160$ \\
\hline
\end{tabular}

* $=r<0.001 ; N=$ No. of specimens.

Table 9. Linear correlation coefficients between compressive properties of cortical bone from the tibias of 6 Caucasian men and cross-sectional area percentages formed by different types of osteons, computed for each bone and averaged (see text for explanation)

\begin{tabular}{lccc}
\hline & $\begin{array}{c}\text { Ultimate } \\
\text { compressive } \\
\text { strength }\end{array}$ & $\begin{array}{c}\text { Modulus } \\
\text { of } \\
\text { elasticity }\end{array}$ & $\begin{array}{c}\text { Compressive } \\
\text { strain }\end{array}$ \\
& $(N=65 ; D F=47)$ & $(N=65 ; D F=47)$ & $(N=65 ; D F=43)$ \\
\hline Light osteons & -0.050 & -0.117 & $0.400^{*}$ \\
Intermediate osteons & $0.480 \dagger$ & -0.255 & 0.071 \\
Dark osteons & 0.125 & 0.102 & -0.010 \\
\hline
\end{tabular}

$*=p<0.01 ; \dagger=p<0.001 ; N=$ No. of specimens; $D F=$ degrees-of-freedom. 
Table 10. Linear correlation coefficients between compressive properties of cortical bone specimens containing over 75 per cent of haversian bone, obtained from tibias of 6 Caucasian men, and cross-sectional area percentages formed by different types of osteons, computed for each bone and averaged (see text for explanation)

\begin{tabular}{lccc}
\hline & $\begin{array}{c}\text { Ultimate } \\
\text { compressive } \\
\text { strength }\end{array}$ & $\begin{array}{c}\text { Modulus } \\
\text { of } \\
\text { elasticity }\end{array}$ & $\begin{array}{c}\text { Compressive } \\
\text { strain }\end{array}$ \\
\hline Light osteons & -0.158 & -0.135 & $(N=58 ; D F=301$ \\
Intermediate osteons & $0.520^{*}$ & 0.003 & $0.435 \dagger$ \\
Dark osteons & 0.102 & 0.108 & 0.389 \\
\hline
\end{tabular}

$*=p<0.01: \dagger=p<0.02: N=$ No. of specimens: $D F=$ degrees-of-freedom.

compressive strain) and the various histological components of the specimens (Table 11).

\section{DISCL SSION}

The correlation coefficients found for our data do not entirely agree nor disagree with those that might be expected from our previous studies on tensile properties of bone or from the studies of Ascenzi and Bonucci (1968) on the compressive properties of individual osteons. Significant positive correlations between light osteons and compressive strength and between dark osteons and compressive strain as well as the significant negative correlations between dark osteons and compressive strength and between light osteons and compressive strain were predicted. A highly significant negative correlation between compressive strength and the percentage of spaces in the cross-sectional area was anticipated but no significant correlations between mechanical properties and internediate osteons were expected.
In order to compare our results with those of Ascenzi and Bonucci for individual osteons, 14 of our specimens with a large proportion of interstitial lamellae were excluded so that our sample consistcd of 51 specimens with more than 75 per cent haversian bone. With the smaller sample (51 specimens) the correlation between compressive strength and intermediate osteons (Table 8) was considerably higher than with the entire sample of 65 specimens (Table 5). However. the correlation between compressive strain and light osteons, although still significant. was slightly reduced in value. No new significant correlations were found.

When the correlation coefficients between the compressive properties and various osteon types of the individual bones were averaged for both the original (Table 9) and the reduced (Table 10) sample, the results confirmed the significant relations obtained for the entire sample without regard to the individual bones (Table 5).

The differences between our findings and those of Ascenzi and Bonucci (1968) for individual osteons may

Table 11. Multiple correlation coefficients between compressive properties of 65 specimens of cortical bone from tibias of 6 Caucasian men and all histologic and microradiographic variables

\begin{tabular}{|c|c|c|c|}
\hline $\begin{array}{l}\text { Dependent } \\
\text { varriable }\end{array}$ & $\begin{array}{l}\text { Independent } \\
\text { variables }\end{array}$ & $\begin{array}{l}\text { Multiple } \\
\text { correlation } \\
\text { coefficient }\end{array}$ & $\begin{array}{c}\text { Adjusted } \\
\text { multiple } \\
\text { correlation } \\
\text { coefficient }\end{array}$ \\
\hline Ult. compressive strength & $\begin{array}{l}\text { Sp, SR, DF,IL. } \\
D O, M R, L F, L O, I R\end{array}$ & 0.714 & $0.65 t$ \\
\hline Modulus of clasticity & $\begin{array}{l}M R, I L, D R, I F \\
S p . L F, D O, S R, L O\end{array}$ & 0.513 & $0.37 *$ \\
\hline Compressive strain & $\begin{array}{l}L O, S p, I L . M R . \\
I O, I R, S R . L F, I F\end{array}$ & 0.690 & 0.611 \\
\hline
\end{tabular}

${ }^{*}=p<0.01 ; \dagger=p<0.001 ; L O=$ light osteons; $I O=$ intermediate osteons; $D O=$ dark osteons; $L F=$ light fragments $I F=$ intermediate fragments; $D F=$ dark fragments; $S R=$ slight radiolucency; $I R=$ intermediate radiolucency; $M R=$ marked radiolucency; $I L=$ interstitial lamellae; Sp $=$ spaces. 
be explained, at least in part, by the following observations:

(1) Their type 1 osteons, which showed the highest compressive strength were never found in our sections. Our light osteons resembled those illustrated in their paper as type 2 . We do not know whether this is a consequence of our sections being much thinner ( $70 \mathrm{vs}$ $500 \mu \mathrm{m}$ ) or of our tibial specimens simply not containing the type of osteon they found in their femoral specimens. Smith (1960) also did not find their type 1 osteons in his study on collagen fiber orientation in human secondary osteons. Smith's sections came from femurs and tibias and were $5 \mu \mathrm{m}$ thick.

(2) Our dark osteons were similar to their type 3 osteons. However, before testing their specimens, Ascenzi and Bonucci cut out the light lamella usually found in the periphery of the osteons. Our dark osteons showed this lamella in most cases. An inner light lamclla, adjacent to the haversian canal, was also frequently observed. According to Gebhardt's theory (1905), the presence of these light lamellae should markedly change the compressive properties of the dark osteons.

(3) Ascenzi and Bonucci did not test osteons corresponding to our intermediate type which formed 17.9 per cent of the break area in our specimens. Intermediate osteons had several light lamellae alternating with dark areas of variable width. The light and dark areas were approximately equal.

(4) Osteons are roughly cylindrical structures which tend to become shorter and thicker with pressure along their longitudinal axis. This tendency is resisted by circularly arranged collagen fibers. In osteon fragments collagen fibers do not form a complete circle and, consequently, are not well adapted to withstand compressive loads. The presence of osteon fragments and interstitial lamellae in our specimens may have affected their mechanical properties differently from those of osteons alone. This supposition was confirmed when osteons and osteon fragments of the same type were considered as a single variable and correlation coefficients with the compressive properties were computed (Table 6). These correlations were generally lower than those obtained for osteonsalone and were not significant except for the correlation between compressive strain and the group of light osteons and fragments which was still significant $(p<0-01)$.

It is interesting to note that, although dark osteons were more abundant than the other types (Table 3), no significant correlations were found between them and the compressive properties of the specimens. Light osteons were much scarcer, which might account for the lack of correlation between them and compressive strength. A similar study using femoral specimens, is in progress as femoral bone has a much higher proportion of light osteons than tibial bone (Evans and Vincentelli, 1969).

Comparison of the data obtained in this study with those of Evans and Bang provided some interesting evidence on the relation of osteons, regardless of their collagen fiber orientation, to the strength characteristics of adult human cortical bone. The significant positive correlation we found between the percentage of osteons in the cross-sectional area and the compressive strength for the whole sample $(r=0.474)$, for the reduced sample $(r=0.464)$, and for the reduced sample when averages of individual bone values were used $(r=0 \cdot 430)$ suggests that osteons tend to increase the compressive strength of bone. This is contrary to their apparent effect on the tensile strength of bone as Evans and Bang found a significant negative correlation between tensile strength and the percentage of osteons in the cross-sectional area. Thus, the more osteons in a given picce of bonc the higher is its compressive and the lower is its tensile strength.

In order to determine if the correlation between osteons (as a group) and compressive strength was responsible for the correlation between compressive strength and intermediate osteons partial correlation coefficients were calculated after the osteon group was partialed out. No significant correlation coefficients were found when the whole sample (65 specimens) was used in the calculation but with the reduced sample (51 specimens) a significant $(p<0.01)$ partial correlation was obtained $\left(r_{\text {partial }}=0.397\right)$. A similar value $\left(r_{\text {partial }}=0.387\right)$ was encountered in the calculations when the individual bone values were used. However, this partial correlation was not significant. This result was probably a consequence of the very marked reduction in the degrees-of-freedom that occur when this averaging procedure is used rather than the actual correlation being too low. In point of fact, the actual correlation is very close to that obtained when the same 51 specimens were used as a single group.

Repeating these calculations, using compressive strain and light osteons as the correlated variables and osteons (as a group) as the partialed out variables, significant $(p<0.01)$ partial correlations were found in all cases.

These results confirm the existence of a significant positive correlation between compressive strength and intermediate osteons as well as between compressive strain and light osteons, when these histologic variables are expressed as percentages of the cross-sectional area of the specimens used in the determination of the mechanical properties. The correlations are a result of the collagen fiber orientation in the intermediate and the light osteons rather than the mere fact that they 
are osteons. Thus, collagen fiber orientation plays an important role in relation to the compressive properties of human cortical bone.

Generally, the correlations between compressive properties of our specimens and the percentage of the cross-section formed by areas with various degrees of calcification were low and nonsignificant (Table 7). The significant positive correlation $(p>0.01)$ between the slightly radiolucent group and compressive strength is in agreement with our anticipations. We have no explanation. however, for the positive correlation between the least calcified group and modulus of elasticity, unless we assume it to be an accidental finding attributable to the very small percentage $(2.5$ per cent $)$ of the cross-section formed by the markedly radiolucent area.

Currey (1959) reported a higher tensile strength in bovine primary bune than in bovine haversian bone. Hert et al. (1965) found bovine primary bone, when tested in an axial direction. had a lower compressive strength than hovine haversian bone. Rovine primary bone has a structure similar. but not equal to. the interstitial lamellae of our human tibial specimens. No significant correlations were found in our study. however. between interstitial lamellae and any of the compressive properties. It is our impression that specimens composed of only one histological type of bone will have to be tested to clarify the role different types of bone tissue play in the mechanical behavior of bone. Such a project is being undertaken.

\section{SL MMARY AND CONCLUSIONS}

(1) The ultimate compressive strength, compressive strain and modulus of elasticity were determined for 65 standardized specimens of unembalmed cortical bone from the various thirds and quadrants of tibias of six men.

(2) Mean compressive strength was greatest in middle third and posterior quadrant specimens and lowest in distal third and anterior quadrant specimens. Proximal third and posterior quadrant specimens had the highest and middle third lateral quadrant specimens the lowest mean compressive strain. Mean modulus of elasticity was greatest in distal third and anterior quadrant specimens and least in those from the proximal third and lateral quadrant.

(3) Compressive strength was least in the 26-yr-old man, increased to a maximum in the 31 -yr-old man, then progressively declined with advancing age. Modulus was greatest in the 26-yr-old man, then steadily declined with age while compressive strain increased from 26 to $54 \mathrm{yr}$ of age, declined to a mini- mum at 61 years then increalsed to a maximum at $75 \mathrm{yr}$ of age.

(4) Cross-sections, taken as close to the fracture site as possible, were studied by polarized light microscopy and by microradiography.

(5) Osteons and their fragments were classified as light, intermediate or dark on the basis of their collagen fiber orientation. as determined from their appearance in polarized lighi.

(6) According to their radiolucency, osteons and their fragments were categorized as slight. intermediate or marked radiolucent.

(7) Ultimate compressive strength had significant positive correlations with the percentages of the cross. section formed by intermediate osteons or by slightly radiolucent osteons and fragments.

(8) Ultimate compressive strength had a highly significant negative correlation with the percentage of the cross-sectional area formed by spaces.

(9) Compressive strain had a significant positive correlation with the percent of the cross-sectional area formed by light osteons.

(10) Multiple correlation coefficients between ultimate compressive strength or compressive strain and the various histologic and microradiographic variables were higher and more significant than that found with modulus of elasticity as a dependent variable.

(11) The significant correlation between compressive strength of the specimens and the percentage of osteons in the break area suggests that osteons tend to increase compressive strength of bone. This relationship was true regardless of the collagen fiber orientation in the osteons.

Ackmowledgements The aluthors wish to acknowledge the assistance of Miss Esther Schaeffer. Statistician. Statistical Research Laboratory, The University of Michigan. and $\mathrm{Mr}$. Edgar Galindez. Dental Materials Center. Central University of Venezuela in the statistical analysis of their data.

\section{REFERENCES}

Ascenzi. A. and Bonucei, E. (1967) The tensile properties of single osteons. 4nat. Rer. 158, 375-386.

Ascenzi. A. and Bonucci, E. (1968) The compressive properties of single osteons. Anat. Rec. 161. 377-392.

Ascenzi, A. and Bonucci. E. (1972) The shearing properties of single osteons. Anat. Rec. 172, $499-510$.

Avery, J. K., Knapp. D. E. and Dempster. W. T. (1959) An infiltration and clearing technic to reveal the vascular pattern of ethylene-diamine-treated cortical bone. Stain Téchn. 34, $213 \cdots 217$.

Evans, F. G. and Bang. S. (1966) Physical and histological differenes between human fibukar and femoral compact hone. In Studies on The Anaromy and Function of Bone und Joints (Edited by Evans. F. G.). pp. 142 155. Springer. Berlin.

Evans. F. G. and Bang. S. (1967) Differences and relationships between physical properties and the microscopic 
structure of human femoral, tibial and fibular cortical bone. Am. J. Anat. 120, 79-88.

Evans, F. G. and Riolo, M. (1970) Relations between fatigue life and histology of adult human cortical bone. J. Bone It Surg. 52-A, 1579-1586.

Gebhardt, W. (1905) Uber funktionell wichtige Anordungs- weisen der feineren und gröberen Bauelemente des Wirbeltierknochen. Arch. Entwickl. Mech. 20, 187-322.

Smith. J. W. (1960) The arrangement of collagen fibers in human secondary osteones. J. Bone Jt Surg. 42-B, 588-605.

Vincentelli, R. and Evans, F. G. (1971) Relations among mechanical properties, collagen fibers, and calcification in adult human cortical bone. J. Biomechanics 4, 193-201. 